\title{
MODELING OF OPTIMAL CREDIT STRATEGY OF A PHARMACEUTICAL PRODUCT DISTRIBUTOR WITH DELAY
}

\section{Myroslav Boychuk}

Chernivtsi National University, Chernivtsi, Ukraine

\author{
Olena Yaroshenko
}

Chernivtsi National University, Chernivtsi, Ukraine

OMESTE

JEL Category: C61, D30

\begin{abstract}
The activities of pharmaceutical products distribution companies are multifaceted. They establish contacts with producers and consumers, determine the range of prices of medicines, do promotions, hold stocks of pharmaceuticals and take risks in their further selling. Therefore, the usage of mathematical models to research into ways of optimizing the management of pharmaceutical products distribution companies considering payments is of great current interest.

The purpose of the paper is to present a model of optimal credit strategy of a distribution company on the pharmaceutical products market considering late delivery. In the mathematical terms, the given problem is the one of optimal control, where a number of pharmaceutical products act as a phase trajectory and the amount of credit granted to a distribution company is a control. To tackle the problem sufficient optimality conditions are used. It is established that the model of optimal credit strategy of a distributor with the delay has two modes of crediting (full and no credit) and the optimal mode. The structure of the optimal process for the given model is also described.
\end{abstract}

Keywords: Distribution, decision-making, optimal control, differential equations, deterministic models

\section{INTRODUCTION}

The pharmaceutical market is a system of interdependent and interacting subjects and objects of production, distribution, and consumption of pharmaceuticals. It is characterized by high rates of profitability due to the specificity of drug products and attracts many

Address of the corresponding author:

Olena Yaroshenko

莑三” o.yaroshenko@chnu.edu.ua participants: manufacturers, intermediaries, pharmacists and others.

Today the Ukrainian pharmaceutical market has formed an extensive network of intermediaries, which includes:

- large distribution companies that receive great quantities of pharmaceuticals from foreign and domestic manufacturers;

- wholesale intermediaries that can receive relatively small shipments of drugs from 
foreign and home manufacturers or from distribution companies;

- retail intermediaries.

They all play an important role and are economically advantageous of manufacturers because:

- many producers are deprived of the possibility to establish a direct contact with product consumers due to territorial isolation;

- it is more profitable for producers to invest into their core business, instead of carrying out marketing activities;

- distributors can provide consumers with the necessary range of medicines and highquality service based on their own experience and qualifications.

Therefore, taking into consideration the pressing problems of the transitional economy in Ukraine, it is of vital importance now the optimization of business and economic activities of distribution companies which will allow them to maintain and strengthen their status on the market, to develop sustainably and to ensure profit growth of owners as well as of employees.

We believe that the system analysis principles and methods of economic-mathematical modeling, considering the huge potential, enables to understand better the causes of the stated problems, to investigate the performance of an economic system on the whole and the development of processes occurring in it. This allows not only to determine possible scenarios of the development of the target object but also to adjust policies pursued in the health care system.

Hrygorkiv and Yaroshenko's paper (2007) proposes a model of a realtor's optimal credit strategy without delay and carries out its investigation applying the necessary optimality conditions (Pontryagin's principle). Whereas in Boychuk \& Yaroshenko's work (Boychuk \& Yaroshenko, 2015)the model of optimal credit strategy of a distributor on the market of pharmaceutical products without delay is studied and researched using sufficient optimality conditions. On the basis of the latter, in the given paper we will construct a model of the optimal credit strategy of a distributor on the pharmaceutical products market considering product late delivery and will conduct its study.

\section{MODEL BUILDING}

Let at any point of time $t \in\left[t_{0}, T\right]$ ( $T$ - planning horizon) a distributor has the ability to take a money loan totaling $k(t)$ at a constant interest rate $p$. He uses the credit to purchase some number of pharmaceutical products $v(t)$ with the aim of it selling and earning the good profit.

Let us assume that increase in the volume of goods $\dot{v}(t)$ in time $t$ in monetary equivalent equals the amount of credit $k(t)$ excluding the volume of goods sold $\alpha v(t)$ ( $\alpha$ - coefficient of sales) and taking into account the volume of product $\beta v(t-\tau)$ ) with late delivery $\tau(\beta-$ product delivery ratio), i.e.

$$
\dot{v}(t)=k(t)-\alpha v(t)+\beta v(t-\tau), t \in\left[t_{0}, T\right],
$$

where $\alpha>0$ and $\beta>0$ - constant, $t_{0} \geq 0, T>t_{0}$, $\tau$ - late delivery

This differential model must be supplemented by the initial condition of prehistory of volume of goods trafficking in the time period $\left[t_{0}-\tau, t_{0}\right]$

$$
v(\theta)=v_{0}(\theta), \theta \in\left[t_{0}-\tau, t_{0}\right],
$$

where $v_{0}-$ piecewise continuous (continuous) function on $\left[t_{0}-\tau, t_{0}\right]$.

Since the credit amount is always a finite quantity, the above ratios should be complemented by the restriction

$$
0 \leq k(t) \leq k_{0}, t \in\left[t_{0}, T\right],
$$

where $k_{0}$ - the set upper bound of limitations on the credit amount.

Restrictions are also imposed on the profit from the sale of goods

$$
\gamma \alpha v(t)-\beta v(t-\tau)-p k(t) \geq \varepsilon, t \in\left[t_{0}, T\right],
$$

where $\gamma$-income from each item of the goods sold (in ratio), $p$ - the credit interest rate (in ratio), $\varepsilon \geq 0$ - minimum profit.

Then a distributor's task is to maximize the total (integral) profit from the sale of goods in the wholetime interval $\left[t_{0}, T\right]$, i.e. 
$\Phi=\int_{t_{0}}^{T}[\gamma \alpha v(t)-\beta v(t-\tau)-p k(t)] d t \rightarrow \max _{k}$

In the mathematical terms, the problem (1) - (5) is the optimal control problem where the volume of goods is a phase trajectory $v$, and the credit amount acts as a control $k$.

\section{MODEL STUDY}

To study the optimal control problem (1) - (5) we use sufficient conditions for optimization that are presented by (Boychuk \& Semchuk, 2012) or (Andreeva, Kolmanovskiy, \& Shayhet, 1992). For this purpose, the following steps will be taken:

- construction of the left crediting process;

- determining the moment of switching of credit control;

- selection of the right crediting process;

- formation of the optimal credit process.

\subsection{Left crediting process}

Under the sufficient optimality conditions for the problem (1) - (3), (5) it is enough to optimize the function of many variables (Boychuk \& Semchuk, 2012)or (Andreeva, Kolmanovskiy, \& Shayhet, 1992)

$R\left(t, k, v(t), v(t-\tau), V_{0}, V_{1}\right) \equiv \dot{b}(t)+\dot{V}_{0}(t) v(t)+\dot{V}_{1}(t-\tau) \times$

$\times v(t-\tau)+\left[V_{0}(t)+V_{1}(t)\right][k(t)-\alpha v(t)+\beta v(t-\tau)]+$

$+\gamma \alpha v(t)-\beta v(t-\tau)-p k(t) \rightarrow \max _{k, v(t), v(t-\tau)}$,

Where the required functions $b, V_{0}$ and $V_{1}$ - are continuously differentiable on $\left[t_{0}, T\right], V_{1}(t) \equiv 0$ if $t \in(T-\tau, T]$.

To take into consideration the restriction (4) we will use the method of Lagrange in accordance with which we must maximize an auxiliary function

$\bar{R}\left(t, k, v(t), v(t-\tau), V_{0}, V_{1}, \chi\right) \equiv R\left(t, k, v(t), v(t-\tau), V_{0}, V_{1}\right)$

$+\chi[\varepsilon-\gamma \alpha v(t)+\beta v(t-\tau)+p k(t)] \rightarrow \max _{k, v(t), v(t-\tau)}$,

where $\chi$-Lagrange multiplier.

Writing down unnecessary condition for the optimality of the function $\bar{R}$ on $\chi$, that is, the partial derivative equals zero, $\frac{\partial \bar{R}}{\partial \chi}$, we obtain the equation

$$
\varepsilon+p k(t)-\gamma \alpha v(t)+\beta v(t-\tau)=0, t \in\left[t_{0}, T\right] .
$$

Function $\bar{R}$, using the equation (8), coincides with the function $R$.

For variables $v(t)$ and $v(t-\tau)$ coefficients of these variables in function $R$ equate to zero for these variables were arbitrary in the areas of their change. We obtain a system of equations

$$
\left\{\begin{array}{l}
\dot{V}_{0}(t)-\alpha\left[V_{0}(t)+V_{1}(t)\right]+\gamma \alpha=0, \\
\dot{V}_{1}(t-\tau)+\beta\left[V_{0}(t)+V_{1}(t)\right]-\beta=0, t \in\left[t_{0}, T\right] .
\end{array}\right.
$$

Function $R$ on the amount of crediting $k$ is linear, and therefore the highest value of $k$ received with the optimizing value of control over crediting (10)

$$
k_{\text {opt }}(t)=\left\{\begin{array}{l}
k_{0}, \quad \text { if } V_{0}(t)+V_{1}(t)-p>0, \\
0, \quad \text { if } V_{0}(t)+V_{1}(t)-p<0, \\
\text { any from }\left[0, k_{0}\right], \text { if } V_{0}(t)+V_{1}(t)-p=0,
\end{array}\right.
$$

$t \in\left[t_{0}, T\right]$

Let's consider the case $V_{0}(t)+V_{1}(t)-p=0$. From system (9) applying integration we get

$$
V_{0}(t)=\alpha(p-\gamma) t, \quad V_{1}(t-\tau)=-\beta(p-1)(t-\tau)
$$

and respectively

$$
V_{0}(t)+V_{1}(t) \equiv[\alpha(p-\gamma)-\beta(p-1)] t=p .
$$

This means that equation must be performed

$$
[\alpha(p-\gamma)-\beta(p-1)] v(t) t=p v(t),
$$

that happens if

$$
v(t)=0, t \in\left[t_{0}, T\right] .
$$

The validity of this transition can be checked with the substitution of $v=0$ in the function $R$, since if $b \equiv$ const the required function is (Andreeva, Kolmanovskiy, \& Shayhet, 1992).

Substituting $v=0$ in equation (1), we get that $k=0$. Thus, from (10) we have two optimization variables on control 
$k_{\text {opt }}(t)=\left\{\begin{array}{l}k_{0}, \text { if } V_{0}(t)+V_{1}(t)-p>0, \\ 0, \text { if } V_{0}(t)+V_{1}(t)-p \leq 0,\end{array} t \in\left[t_{0}, T\right]\right.$

Let set the full credit mode as the left control

$$
k_{\text {left }}(t)=k_{\text {opt }}(t)=k_{0} .
$$

As a result, we have two credit modes:

$k_{\text {opt }}(t)=k_{0}, t \in\left[t_{0}, T\right]$ - full credit mode

$k_{\text {opt }}(t)=0, t \in\left[t_{0}, T\right]-$ absence of credit.

Corresponding to it, the left trajectory of the volume of goods $v_{\text {left }}(t), t \in\left[t_{0}, T\right]$ is determined from the original problem (1), (2) if $k_{\text {left }}=k_{0}$ applying the method of steps (Elsgolts \& Norkin, 1971, p. 17).

The essence of the method of steps is in the following. In accordance with the previous history $v_{0}(\theta), \theta \in\left[t_{0}-\tau, t_{0}\right]$ from (1)-(2) determine $v^{(1)}(t)$, $t \in\left[t_{0}, t_{0}+\tau\right]$. Then after $v^{(1)}(t), t \in\left[t_{0}, t_{0}+\tau\right]$ find $v^{(2)}(t), t \in\left[t_{0}+\tau, t_{0}+2 \tau\right]$ and so on. For $v^{(N)}(t)$, $t \in\left[t_{0}+(N-1) \tau, t_{0}+N \tau\right] \quad$ calculate $v^{(N+1)}(t)$, $t \in\left[t_{0}+N \tau, T\right]$, where $N$-integral part of a number $\left(T-t_{0}\right) \tau^{-1}$.

In this case, the left trajectory $v(t)$ is piecewise differentiated (piecewise continuous and differentiated) function on $\left[t_{0}, T\right]$.

Then the left credit process is $k_{\text {left }}(t)=\left\{k_{0}, v_{\text {left }}(t), t \in\left[t_{0}, \zeta\right]\right\}$. It is necessary to establish for this the moment of switching control over crediting $\zeta$.

\subsection{The moment of switching of credit control}

Substituting $k=k_{0}$ and $v(t)=v_{\text {left }}(t)$ in the equation (8) we obtain a nonlinear algebraic equation

$$
\varepsilon+p k_{0}-\gamma \alpha v_{\text {left }}(t)+\beta v_{\text {left }}(t-\tau)=0, t \in\left[t_{0}, T\right],
$$

which can be solved by one of the numerical techniques (Yasynskyi, 2005, pp. 25-40) or
(Vasilyev, 1980, pp. 17-73).In such a way, we define the moment of switching of credit control $\zeta$.

\subsection{Right crediting process}

As the right control, we will take the condition of the absence of crediting $k_{\text {right }}(t)=0, t \in[\zeta, T]$. We determine the appropriate right path per the amount of crediting $v_{\text {right }}(t), t \in[\zeta, T]$ by the right control of the amount of crediting $k_{\text {right }}=0$ in the original task

$$
\begin{gathered}
\dot{v}(t)=-\alpha v(t)+\beta v(t-\tau), t \in[\zeta, T] \\
v(\theta)=v_{\text {left }}(\theta), \theta \in[\zeta-\tau, \zeta] .
\end{gathered}
$$

This original problem with the prehistory can be solved by the combined use of the method of steps (Elsgolts \& Norkin, 1971, p. 17) and the numerical method of Runge-Kutta (Yasynskyi, 2005, pp. 167-181). It should be noted that the right path $v_{\text {right }}(t)$ is a continuous and piecewise differentiated function on $\left[t_{0}, T\right]$.

As a result, we get the right process

$$
\left\{k_{\text {right }}=0, v_{\text {right }}(t), t \in[\zeta, T]\right\} .
$$

\subsection{The optimal process of crediting}

According to the results reported in (Boychuk \& Semchuk, 2012) or (Andreeva, Kolmanovskiy, \& Shayhet, 1992)bonding at the time of switching of credit control $t=\zeta$ of the left $\left\{k_{\text {left }}(t)=k_{0}, v_{\text {left }}(t), t \in\left[t_{0}, \zeta\right]\right\} \quad$ and the right $\left\{k_{\text {right }}(t)=0, v_{\text {right }}(t), t \in[\zeta, T]\right\}$ processes gives the optimal crediting process $\left\{k_{\mathrm{opt}}, v_{\mathrm{opt}}(t), t \in\left[t_{0}, T\right]\right\}$, i.e.

$$
\begin{gathered}
k_{\mathrm{opt}}(t)=\left\{\begin{array}{l}
k_{0}, \text { if } t \in\left[t_{0}, \zeta\right), \\
0, \text { if } t \in[\zeta, T],
\end{array}\right. \\
v_{\mathrm{opt}}(t)=\left\{\begin{array}{l}
v_{\text {left }}(t), \text { if } t \in\left[t_{0}, \zeta\right], \\
v_{\text {right }}(t), \text { if } t \in[\zeta, T] .
\end{array}\right.
\end{gathered}
$$

This optimal control according to the amount of crediting $k_{\mathrm{opt}}$ is a piecewise continuous function, and the optimal trajectory in relation to the volume of goods is a continuous and piecewise differentiated function on $\left[t_{0}, T\right]$. 
Profits from the sale of goods is determined by the formula

$$
\Phi=\int_{t_{0}}^{T}\left[\gamma \alpha v_{\mathrm{opt}}(t)+\beta v_{\mathrm{opt}}(t-\tau)-p k_{\mathrm{opt}}(t)\right] d t,
$$

calculation of which can be done with the help of one of numerical integration methods (Yasynskyi, 2005, pp. 99-128).

It is necessary to note that the above-described method is possible at piecewise constant interest rate

$$
p(t)=\left\{\begin{array}{l}
p_{1}, \text { if } t_{0} \leq t<T_{1}, \\
p_{2}, \text { if } T_{1} \leq t<T_{2}, \\
\cdots \\
p_{L}, \text { if } T_{L-1} \leq t \leq T_{L} \equiv T .
\end{array}\right.
$$

\section{CONCLUSIONS}

The model is suggested of the optimal credit strategy of a distributor on the pharmaceutical products market with late delivery and its investigation is conducted.

It is established that the model of the optimal credit strategy of a distributor with late delivery has two modes of crediting (full and absence of credit) and the optimal mode.

The structure an optimal process for the model of optimal credit strategy of a distributor with late delivery is described.

\section{WORKS CITED}

Andreeva, E., Kolmanovskiy, E., \& Shayhet, L. (1992). Management systems with aftereffect. Moscow: Publishing House "Nauka".

Boychuk, M., \& Semchuk, A. (2012). Modeling and optimization of full cycle one-product macroeconomic growth taking into account environmental factors. Chernivtsi: Zoloti litavry.

Boychuk, M., \& Yaroshenko, O. (2015). Credit strategy optimization of a distributing company on the pharmaceutical market. Scientific journal of Bukovyna State University of Finance and Economics, 28, 258-263.

Elsgolts, L., \& Norkin, S. (1971). Introduction to the Theory of Differential Equations with Deviating Arguments. Moscow: Publishing House "Nauka".

Hrygorkiv, V., \& Yaroshenko, O. (2007). Modelyuvannya optymal'noyi kredytnoyi stratehiyi rieltora. Economic cybernetics: scientific journal, 1-2(43-44), 4-9.

Vasilyev, F. (1980). Numerical methods for solving extreme problems. Moscow: Publishing House "Nauka".

Yasynskyi, V. (2005). Fundamentals of computational methods. Chernivtsi: Zoloti litavry.

Received for publication: 07.07.2016

Revision received: $\quad 21.08 .2016$

Accepted for publication: 20.01.2017

\section{How to cite this article?}

Style - APA Sixth Edition:

Boychuk, M., \& Yaroshenko, O. (2017, July 15). Modeling of optimal credit strategy of a pharmaceutical product distributor with delay. (Z. Čekerevac, Ed.) MEST Journal, 5(2), 1-6. doi:10.12709/mest.05.05.02.01 
Style - Chicago Sixteenth Edition:

Boychuk, Myroslav, and Olena Yaroshenko. "Modeling of optimal credit strategy of a pharmaceutical product distributor with delay." Edited by Zoran Čekerevac. MEST Journal (MESTE) 5, no. 2 (July 2017): 1-6.

Style - GOST Name Sort:

Boychuk Myroslav and Yaroshenko Olena Modeling of optimal credit strategy of a pharmaceutical product distributor with delay [Journal] // MEST Journal / ed. Čekerevac Zoran. - Toronto - Belgrade : MESTE, July 15, 2017. - 2 : Vol. 5. - pp. 1-6.

Style - Harvard Anglia:

Boychuk, M. \& Yaroshenko, O., 2017. Modeling of optimal credit strategy of a pharmaceutical product distributor with delay. MEST Journal, 15 July, 5(2), pp. 1-6.

Style - ISO 690 Numerical Reference:

Modeling of optimal credit strategy of a pharmaceutical product distributor with delay. Boychuk, Myroslav and Yaroshenko, Olena. [ed.] Zoran Čekerevac. 2, Toronto - Belgrade : MESTE, July 15, 2017, MEST Journal, Vol. 5, pp. 1-6. 